\title{
Balla Lompoa di gowa (Kajian Arsitektur Tradisional Makassar)
}

\author{
A Study on Traditional Architecture of Makassar
}

\author{
Oleh Raodah \\ Balai Pelestarian Sejarah dan Nilai Tradisional Makassar \\ Jln. Sultan Alauddin KM. 7 Makassar \\ Email: raodahtul.janna@yahoo.com
}

Naskah Disetujui: 15 Agustus 2012

\begin{abstract}
Abstrak
Penelitian mengkaji arsitektur tradisional Makassar rumah adat Balla Lompoa, bekas istana Raja Gowa. Rumah adat itu berlokasi di Kota Sungguminasa, Kabupaten Gowa, Sulawesi Selatan. Arsitektur rumah adat Balla Lompoa berbentuk rumah panggung, mencerminkan bentuk kebudayaan masa lampau. Tujuan penelitian, mengungkapkan bentuk dan fungsi ruang, struktur bangunan, ragam hias, kosmologi dalam arsitektur Balla Lompoa. Metode penelitian yang digunakan bersifat deskriptif dengan pendekatan kualitatif. Teknik pengumpulan data berupa wawancara, pengamatan, dan studi pustaka. Hasil penelitian menunjukkan bentuk dan fungsi bangunan Balla Lompoa terdiri dari tiga bagian, yaitu bagian atas disebut loteng atau pammakang, bagian tengah merupakan badan rumah disebut kale balla, dan bagian bawah atau kolong yang disebut passiringan. Arsitekturnya menganut falsafah sulapa appa yang menggambarkan segala aspek kehidupan manusia barulah sempurna jika berbentuk segi empat. Falsafah tersebut direfleksikan pada areal tanah, tiang rumah, jendela dan ruangan.
\end{abstract}

Kata Kunci: Balla lompoa, loteng, kale balla, passiringan dan sulapa appa.

\begin{abstract}
This paper is a result of my research on traditional architecture of adat house Balla Lompoa, former palace of the King of Gowa. It is located in the city of Sungguminasa, Residence of Gowa, South Sulawesi. Balla Lompoa is a rumah panggung (house on stilts) that reflects cultural forms of the past. The aim of the study is to reveal form and function of the rooms, building structure, ornaments, and cosmology in the architecture. This is a descriptive research with qualitative approach. Data was compiled through observation, interviews, and bibliographic study. The result finds that the form and function of Balla Lampoa consist of three parts: upper part is called loteng or pammakang, middle part, which is the body of the house, called kale balla; and the lower part called passiringan. The house conveys philosophical value called sulappa appa, describing that perfect life of a human being is in the form of square. It is applied to the land are, house posts, windows, and rooms.
\end{abstract}

Keywords: Balla lompoa, loteng, kale balla, passiringan, sulapa appa. 


\section{A. PENDAHULUAN}

Arsitektur tradisional adalah salah satu unsur kebudayaan yang tumbuh dan berkembang bersama dengan pertumbuhan suatu suku bangsa. Oleh karena arsitektur tradisional merupakan salah satu identitas dari suatu pendukung kebudayaan, sehingga dalam arsitektur tradisional terkandung secara terpadu aspek ideal, aspek sosial dan aspek material suatu kebudayaan. Unsur kebudayaan itu dihayati, sehingga lahirlah rasa bangga dan rasa cinta terhadap arsitektur tradisional itu. Proses pergeseran kebudayaan di Indonesia, khususnya di pedesaan, telah menyebabkan pergeseran wujud kebudayaan yang terkandung dalam arsitektur tradisional.

Arsitektur sebagai hasil karya seni budaya diakui sebagai salah satu wujud kebudayaan yang dapat dijadikan cerminan dari kehidupan manusianya, dari masa ke masa. Arsitektur sebagai unsur kebudayaan, laksana salah satu bentuk bahasa non verbal manusia yang bernuansa simbolik. Arsitektur adalah alat komunikasi manusia secara nonverbal yang mempunyai nuansa sastrawi, tidak jauh berbeda dengan sastra verbal metaforik. Arsitektur sendiri dapat dipahami melalui wacana metafor keindahan, dari sudut pandang itu akan dikenali karakteristiknya.

Dalam naskah kuno sastra Jawa dan kitab lontara Bugis Makassar secara jelas dapat ditemukan relevansi antara lingkungan dan kehidupan budaya manusia, hal tersebut terwujud pada penggambaran bentuk rumah adat yang diciptakannya.Tata cara pembuatan rumah menurut konsep arsitektur tradisional Sulawesi Selatan, merujuk pada pesan atau wasiat yang bersumber dari kepercayaan dan adat istiadat yang dianut masyarakat Sulawesi Selatan, mulai dari pemilihan tempat, penentuan arah peletakan rumah, bentuk arsitektur, hingga penyelenggaraan upacara ritual ketika proses pembangunannya.

Mardanas, menyatakan bahwa orang-orang dahulu, tata wilayah dan tata bangunan alias arsitektur tidak diarahkan pertama kali demi penikmatan rasa estetika bangunan, tetapi terutama demi kelangsungan hidup secara kosmis (Mardanas, 1985:7). Artinya, sebagai bagian integral dari seluruh kosmos atau semesta raya yang keramat dan gaib.

Arsitektur tradisional budaya lokal Bugis Makassar mengemukakan unsur hiasan yang digunakan pada rumah tradisional yang banyak mengambil bentuk dari flora dan fauna. Sekilas dalam hal rumah tradisional disebutkan bahwa; secara konseptual arsitektur, masyarakat tradisional Sulawesi Selatan (Bugis, Makassar dan Toraja) berangkat dari suatu pandangan hidup ontologis, memahami alam semesta secara universal. Filosofi hidup masyarakat tradisional Bugis Makassar yang disebut sulapa appa, menunjukkan upaya untuk menyempurnakan diri. Filosofi itu menyatakan bahwa segala aspek kehidupan manusia barulah sempurna, jika berbentuk segi empat, yang merupakan mitos asal kejadian manusia yang terdiri dari empat unsur, yaitu: tanah, air, api, dan angin (Tato, 2008:2).

Masyarakat tradisional Bugis Makassar yang berpikiran secara totalitas, pembuatan rumah tradisional mereka dipengaruhi oleh pemahaman struktur kosmos mengacu pada alam yang terbagi atas tiga bagian, yaitu alam atas, alam tengah dan alam bawah. Oleh karena itu rumah tradisional orang Bugis Makassar tersusun dari tiga tingkatan yang berbentuk segi empat, dibangun mengikuti model kosmos menurut pandangan hidup mereka. Anggapan mereka bahwa alam raya (makrokosmos ) tersusun dari tiga tingkatan yaitu: (1) benua atas adalah tempat dewa-dewa yang dipimpin oleh seorang dewa tertinggi yang disebut dewata seuwae (dewa tunggal), bersemayam di botting langik (langit tertinggi), (2) benua tengah adalah bumi yang dihuni oleh wakil-wakil dewa tertinggi yang mengatur hubungan manusia dengan dewa tertinggi serta mengawasi jalannya tata tertib kosmos, dan (3) benua bawah merupakan tempat yang paling dalam dianggap berada di bawah air. Semua 
pranata yang berkaitan dengan pembuatan atau pembangunan rumah harus berdasarkan kosmologis yang diungkapkan dalam bentuk makna simbolis-filosofis, yang diketahuinya secara turun-temurun dari generasi ke generasi (Hamid, 1978:12).

Maraknya perkembangan arsitektur modern yang menghiasi gedung-gedung di perkotaan, keberadaan rumah adat Balla Lompoa seolah-olah terkucilkan oleh kemegahan gedung-gedung mewah yang ada di sekelilingnya. Rumah adat Balla Lompoa, sebagai cerminan arsitektur tradisional Makassar, warisan budaya yang perlu dilestarikan guna memperkokoh ketahanan budaya bangsa. Oleh karena itu, perlu dilakukan pengkajian arsitektur tradisional Balla Lompoa yang merupakan realita kebudayaan masa lampau yang masih bertahan sebagai simbol kejayaan Kerajaan Gowa masa lalu. Pokok permasalahan dalam penelitian ini adalah : 1) Bagaimana konsep arsitektur Balla Lompoa, 2) Bagaimana pandangan kosmologis pada rumah adat Balla Lompoa, dan 3) Bagaimana orientasi arah bangunan Balla Lompoa.

Tujuan penelitian ini untuk mengungkapkan dan mendeskripsikan arsitektur Balla Lompoa. Ruang lingkup penelitian meliputi dua hal yakni wilayah dan materi. Ruang lingkup wilayah penelitian adalah Kabupaten Gowa Provinsi Sulawesi Selatan yang merupakan lokasi Balla Lompoa, dan ruang lingkup materi penelitian meliputi : Sejarah Balla Lompoa, arsitektur yang meliputi bentuk dan fungsi ruang, struktur bangunan, ragam hias, kosmologi Balla Lompoa, orientasi bangunan.

Penelitian ini menggunakan metode deskriptif dengan pendekatan kualitatif tentang arsitektur tradisional Balla lompoa. Data yang dikumpulkan terdiri atas data primer dan data sekunder. Pengumpulan data dilakukan dengan teknik pengamatan, wawancara mendalam terhadap beberapa narasumber, dan studi pustaka. Seluruh data yang terkumpul dianalisis dan disusun dalam bentuk deskripsi

\section{B. HASIL DAN BAHASAN}

\section{Sejarah Balla Lompoa}

Balla Lompoa secara harfiah berarti rumah besar atau rumah kebesaran yang dihuni oleh raja. Balla Lompoa berada di tengah Kota Sungguminasa Kabupaten Gowa, Provinsi Sulawesi Selatan, tepatnya di Jalan Sultan Hasanuddin No 48. Lokasi itu merupakan situs budaya dalam sebuah komplek yang luasnya sekitar tiga hektar. Di bagian belakangnya terdapat tembok batu alam yang tebal dan pintu kayu yang lebar dan kokoh, sedangkan di bagian depannya berpagar permanen yang rendah dan halaman yang terbuka. Di samping bangunan Balla Lompoa terdapat bangunan Istana Tamalate yang ukurannya jauh lebih besar yang dibangun pada era kepemimpinan Bupati Gowa Syahrul Yasin Limpo, tahun 1980-an.

Lokasi Balla Lompoa berjarak kurang lebih 3 kilometer dari Kota Makassar. Arus lalu lintas ke lokasi itu sangat lancar karena berada di jalur yang dilewati pete-pete (angkot). Kawasan ini berada di empat persimpangan jalan, sehingga akses untuk memasuki lokasi tersebut dapat melalui ke empat pintu gerbang. Pintu gerbang utama berada di jalan KH. Wahid Hasyim, pintu gerbang kedua berada di bagian belakang Balla Lompoa yaitu Jalan Andi Mallombassang, pintu gerbang ketiga berada di Jalan Habibu Daeng Kulle dan pintu gerbang keempat berada di Jalan A. Baso Erang. 
Gambar 1. Denah Lokasi Balla Lompoa

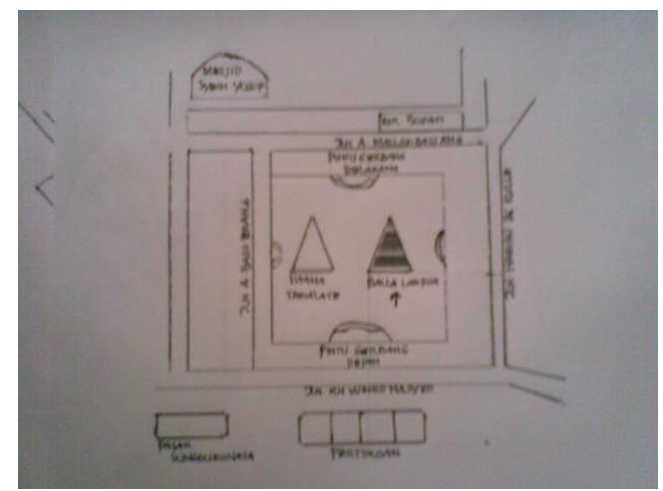

Balla Lompoa dibangun tahun 1936 setelah diangkatnya Raja Gowa XXXV I Mangimangi Daeng Matutu, Karaeng Bontonompo yang bergelar Sultan Muhammad Tahir Muhibuddin. Balla lompoa adalah kediaman raja sekaligus sebagai pusat pemerintahan Kerajaan Gowa. Pembangunan istana dan pusat kegiatan pemerintahan dilakukan sebagai penolakan terhadap salah satu ayat Perjanjian Bungaya yang menyatakan:

- Gerbang-gerbang dan tembok pertahanan Raja Gowa harus dirusakkan dan Raja Gowa tidak boleh lagi mendirikan bangunan - bangunan yang demikian dengan tidak keluasaan kompeni.

- Raja Gowa tidak boleh mendirikan perkampungan, rumah dan sebagainya sampai jauhnya satu hari perjalanan dari pinggir laut.

- Raja Gowa tidak boleh lagi mendirikan benteng-benteng atau kubu-kubu pertahanan. Yang dipertahankan oleh Belanda hanya Benteng Ujung Pandang yang kemudian diganti menjadi Fort Rotterdam sebuah nama tempat kelahiran Spelman ( Pangerang, et al. 2004:26)

Dalam kurun waktu 30 tahun hubungan antara pemerintah Belanda dengan bangsawan tinggi Gowa cenderung baik dan memberi keyakinan kepada Belanda untuk merehabilitasi kembali Kerajaan Gowa, termasuk Bone yang ditaklukkan pada tahun 1905/1906.
Rehabilitasi pada Kerajaan Gowa dan diangkatnya I Mangimangi Daeng Matutu sebagai Raja Gowa XXXV pada tahun 1936, menyebabkan dibangunnya kembali istana Balla Lompoa di Sungguminasa sebagai tempat kediaman raja, sekaligus dijadikan sebagai pusat pemerintahan Kerajaan Gowa. Sebelum Balla Lompoa dibangun, sudah ada tempat kegiatan untuk melaksanakan pemerintahan Kerajaan Gowa, yakni kantor kontrolir onder afdeling yang berlokasi tidak jauh dari Balla Lompoa, hanya diantarai Lapangan Bungaya, tepatnya di lokasi bekas Kantor Bupati Kepala Daerah tingkat II (Limpo,et al. 1995:17).

Balla Lompoa pernah dihuni oleh dua orang raja, yaitu I Mangimangi Daeng Matutu Karaeng Bontonompo Sultan Muhammad Tahir Muhibuddin dan Raja Gowa ke-35 Tumenanga ri Sungguna (tahun 1936 - 1946). Setelah Raja Gowa ke-35 ini meninggal, ia digantikan oleh putranya Andi Ijo Daeng Mattawang Karaeng Lalolang Sultan Muhammad Abdul Kadir Aididdin (Raja Gowa ke-36). Raja Gowa ini juga menempati Balla Lompoa. Dalam pemerintahan Andi Ijo, sistem pemerintahannya berubah dari bentuk swapraja menjadi swatantra dan ia menjadi kepala daerah pertama dengan gelar Sri Raja/Kepala Daerah Gowa (19461960) dengan keputusan Mendagri No.UP. 7/2/24 tanggal 6 Pebruari 1957. Setelah jabatan Andi Ijo berakhir sebagai kepala Daerah Tingkat II Gowa yang pertama, ia pindah ke Jongaya, dan wafat pada tanggal 9 Januari 1978 dan diberi gelar "Tumenanga Ri Jongaya “. (Patunru, 1967:27).

Setelah pemerintahan Andi Ijo berakhir, maka berakhir pulalah sistem Kerajaan Gowa di Balla Lompoa. Fungsi Balla Lompoa di Gowa berubah dari istana kerajaan menjadi museum. Perubahan status ini didasarkan atas SK Bupati KDH Tingkat II Gowa No. 77/AU/1973 Tanggal 11 Desember 1973. Di dalam museum Balla Lompoa itu tersimpan peninggalan benda-benda pusaka Kerajaan Gowa, termasuk benda 
peninggalan Raja Gowa pertama Tumanurunga (1320) yaitu salokoa, berupa mahkota yang telah dipakai oleh raja-raja Gowa. Selain salokoa, terdapat pula benda-benda peninggalan Raja Gowa, seperti ponto janga-jangaya (gelang naga melingkar) yang terbuat dari emas seberat 985,5 gram, pedang sudanga (pedang sakti peninggalan Karaeng Bayo), rante kalompoang (kalung kebesaran) yang terbuat dari emas seberat 2.182 gram, tamadakkaya (mata tombak tiga buah), subang (anting-anting yang terbuat dari emas murni beratnya 287 gram jumlahnya 4 buah) tatarapang (keris yang bersarung emas) kancing gauka ( perlengkapan kerajaan), kolara (rante manila, kalung emas beratnya 270 gram perlengkapan upacara), medali emas, penning emas (pemberian dari Kerajaan Inggeris), cincin gaukang yang terbuat dari emas murni. (Pangerang, et. al. 2004:34).

Benda-benda kerajaan ini masih tetap utuh dan terawat dengan baik dalam museum Balla Lompoa. Selain berfungsi sebagai museum, Balla Lompoa juga berfungsi sebagai tempat pelaksanaan upacara-upacara adat. Salah satu upacara adat yang menjadi agenda tahunan pemerintah Kabupaten Gowa adalah accera kalompoang, yaitu pencucian benda-benda pusaka Kerajaan Gowa yang dilaksanakan setiap bulan Zulhajji atau pada lebaran Idul Adha. Upacara ini berlangsung sejak masa pemerintahan Raja Gowa XIV Sultan Alauddin. Menurut kepercayaan orang-orang Makassar dahulu, bilamana benda-benda kerajaan telah dicuci dan timbangannya berkurang berarti akan ada malapetaka yang akan menimpa negerinya atau tidak mendatangkan keberhasilan, sebaliknya apabila benda pusaka itu dicuci timbangannya lebih berat dari semula pertanda akan dapat mendatangkan kemakmuran bagi masyarakat. (wawancara Tenribali, 15 April 2010).

Masyarakat dan tokoh-tokoh adat di Gowa beranggapan bahwa keberadaan Balla Lompoa bukan saja sebagai museum yang menyimpan benda-benda kerajaan, tetapi rumah adat ini dianggap sebagai tempat keramat, dan mempunyai kekuatan magis, sehingga ada sebagian masyarakat yang datang ke tempat itu untuk meminta berkah kepada Tuhan melalui benda-benda pusaka Kerajaan Gowa. Ada satu kamar khusus yang digunakan untuk menyimpan benda-benda pusaka. Kamar tersebut dilengkapi dengan sesajian seperti seperangkat alat makan, lilin merah, foto Syekh Yusuf dan Sultan Hasanuddin, pisang raja sebagai persembahan yang digunakan untuk melaksanakan ritual. Selain sesajian ada juga ranjang kecil berkelambu merah yang dilengkapi dengan kasur beralas kain warna kuning, pada ranjang kecil itu terdapat kotak kayu tempat penyimpanan benda-benda kerajaan peninggalan Raja Tumanurung.

Gambar 2. Rumah Adat Balla Lompoa

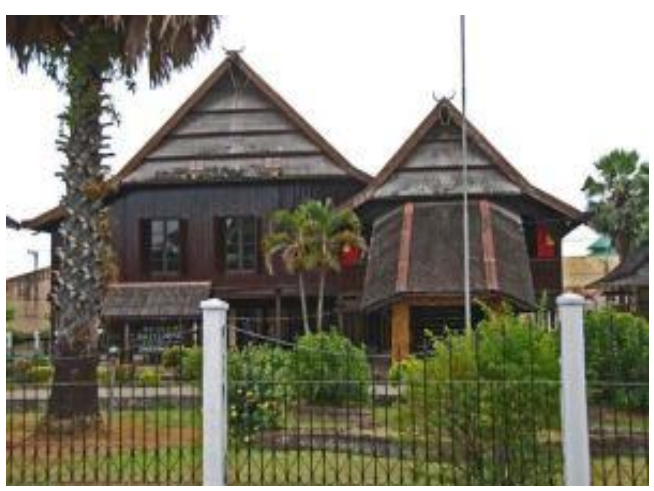

Sumber: Data Penelitian 2010

\section{Arsitekitur Balla Lompoa}

Ditinjau dari aspek arsitektur bangunannya, Balla Lompoa berbentuk rumah panggung yang merupakan refleksi dari rumah adat pada masa Kerajaan Gowa. Karakteristik khas Balla Lompoa pada gilirannya tidak hanya berfungsi sekadar warisan budaya fisik dan jejak historis arkeologis dalam wujud teknofak dan idiofak, tetapi ketertarikan banyak orang akan bangunan bersejarah ini menjadi objek wisata menarik yang senantiasa didambakan orang untuk dikunjungi. Dahulu rumah adat ini berfungsi sebagai tempat kediaman dan pertemuan para pemangku adat Kerajaan Gowa, tetapi dialihfungsikan sebagai 
museum untuk mengenang perjalanan sejarah Kerajaan Gowa.

\section{a. Bentuk dan Fungsi Ruang}

Rumah adat Balla Lompoa terdiri atas tiga bagian, yaitu bagian atas yang disebut loteng atau pammakang, berfungsi sebagai plafon, bagian tengah merupakan badan rumah disebut kale balla, berfungsi sebagai ruang tamu dan kamar tidur, dan bagian bawah atau kolong rumah yang disebut passiringang, berfungsi sebagai tempat kendaraan. Ketiga bagian tersebut melambangkan falsafah sulapa appa.

\section{1) Bagian atas (ulu balla, loteng/pam makang) \\ Atap rumah atau ulu balla,} rangkanya berbentuk prisma dan memakai tutup bubungan yang disebut sambunglayang. Bubungan itu bertingkat lima yang menandakan bahwa penghuni rumah itu adalah raja atau bangsawan tinggi. Berbeda dengan sambunglayang rumah masyarakat biasa atau to maradeka yang hanya terdiri atas satu atau dua tingkatan. Pada sudut atas bubungan (onjong) bagian depan dan belakang, baik pada rumah induk maupun serambi (paladang atau lego-lego) dihiasai oleh replika tanduk kepala kerbau sebagai pertanda derajat kebangsawanan pemilik rumah.

Gambar 3. Ulu balla, dengan Sambulayang Bersusun Lima

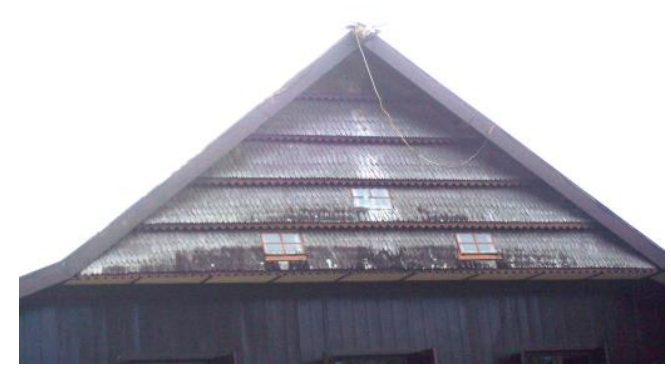

Sumber: Data Penelitian 2010

Atap rumah terbuat dari sirap berwarna hitam yang menutupi badan rumah, bagian depan serambi atau legolego, dan tangga. Atap sirap yang digunakan rumah adat ini terinspirasi oleh bangunan-bangunan arsitektur Belanda, sehingga berbeda dengan atap rumah orang kebanyakan yang hanya menggunakan atap rumbia atau seng. Di bawah atap terdapat ruang yang disebut pammakkang yang juga berfungsi sebagai plafon yang terbuat dari papan berwarna hitam. Dahulu pada rumah masyarakat biasa pammakkang digunakan sebagai lumbung padi, sedang pada Balla Lompoa pammakkang berfungsi sebagai tempat persembunyian dan mengintai musuh ke berbagai arah, seperti tampak pada bagian depan sambung layang yang memiliki tiga ventilasi yang berbentuk segi empat, berukuran $60 \times 60$ sentimeter.

\section{2) Badan rumah (kale balla)}

Rumah induk atau badan rumah Balla Lompoa berukuran 60 x 40 meter terdiri dari tiga bagian, yaitu bagian depan yang disebut paddaserang riolo, bagian tengah disebut paddaserang ritangnga dan di bagian belakang disebut paddaserang riboko. Pada umumnya ruang-ruang itu berbentuk persegi empat yang dibatasi oleh dinding. Setiap dinding memiliki beberapa tiang.

Bagian depan (paddaserang riolo) atau serambi merupakan bangunan tambahan setelah tangga utama. Ruang itu dijadikan tempat persinggahan sebelum tamu memasuki ruang tengah. Ruangan itu sering pula disebut lego-lego atau paladang yang terletak pada bagian kiri badan rumah. Pada masa pemerintahan Kerajaan Gowa, tamu yang akan menghadap raja dipersilahkan duduk sejenak di ruang itu, sebelum menemui raja. Ruangan itu berukuran kira-kira $4 \mathrm{x}$ 4,5 meter. Pada bagian depannya terdapat tangga yang menghubungkan ruangan bawah dan ruang atas. Di samping kanan dan kiri dibatasi oleh dinding yang dibuat hanya setengah dinding rumah dan diberi pengaman atau terali berjumlah 15 batang. Hal ini dimaksudkan agar cahaya dan udara bebas masuk ke ruangan tersebut. Itulah sebabnya ruangan ini bisa juga 
digunakan sebagai tempat beristirahat dan bersenda gurau bagi penghuni rumah. Lantai ruangan ini lebih rendah, kira-kira 50 sentimeter dari ruang tengah, yang terbuat dari papan kayu ulin atau kayu besi berwarna hitam.

Bagian tengah (paddaserang ri tangngah) digunakan sebagai tempat menerima tamu dan sebagai tempat bermusyawarah, serta upacara-upacara ritual. Pada bagian ini cukup luas, yakni kurang lebih 18 × 8 meter. Pada dinding depan terdapat tiga buah jendela kaca yang mirip dengan model jendela bangunanbangunan peninggalan Kolonial Belanda. Jendela pada samping kanan dan kiri berjumlah 6 (enam) buah. Pada ruang ini terdapat koleksi foto raja-raja yang pernah memerintah Kerajaan Gowa, dua payung kebesaran raja Gowa, dan beberapa baju yang pernah dikenakan oleh raja Gowa pada waktu berkuasa. Lantai ruangan terbuat dari kayu papan yang cukup kuat dan masih asli, belum pernah ada pergantian sejak didirikannya Balla Lompoa ( Tenribali,wawancara, 15 April 2010).

Bagian belakang (Paddaserang riboko), merupakan ruang ketiga yang digunakan sebagai ruang tempat tidur dan tempat menyimpan barang-barang peninggalan Kerajaan Gowa yang disebut Gaddong Kalompoang. Di ruangan itu terdapat 2 kamar/bilik yaitu satu kamar digunakan sebagai tempat penyimpanan benda-benda Kerajaan Gowa. Ruangan ini merupakan ruangan khusus dan sangat disakralkan. Oleh sebab itu tidak semua pengunjung dapat memasukinya kecuali tamu khusus seperti tamu negara atau mereka yang masih mempunyai keturunan langsung dengan raja Gowa.

Kamar kedua adalah tempat tidur raja. Kamar itu berdampingan dengan kamar atau ruangan penyimpanan bendabenda pusaka. Hal ini dimaksudkan agar kekuatan benda-benda kerajaan senantisa menjadi sumber kekuatan bagi raja yang berkuasa di masa itu. Di depan ruang kamar tidur raja terdapat ruang makan raja, dan di sebelah ruang makan terdapat ruang patala (ruang tempat menghidangkan makanan). Ruangan di belakangnya adalah koridor yang berfungsi sebagai ruang tunggu raja. Di depan ruang koridor, yakni di samping kiri dan kanan, berderet kamar tidur yang digunakan sebagai ruang tidur permaisuri dan anak-anaknya.

Fungsi ruangan-ruangan tersebut tidaklah seperti yang terlihat sekarang ini. Setelah berakhirnya sistem pemerintahan Kerajaan Gowa, kedua fungsi kamar itu yakni kamar raja dan kamar permaisuri, berubah menjadi tempat penyimpanan koleksi benda-benda peninggalan Kerajaan Gowa masa lalu.

\section{3) Bagian bawah rumah (passiringan)}

\section{Pada bagian bawah rumah Balla}

Lompoa terlihat tiang-tiang kokoh penyangga badan rumah. Tiang rumah adat itu berjumlah 78 buah, terbuat dari kayu jati yang cukup kuat, sehingga tiang ini belum pernah diganti sejak rumah ini dibangun. Tiangnya berbentuk segi empat yang disangga oleh fondasi beton segi empat. Pada rangka yang menopang lantai rumah terdapat balok yang disusun melintang dan membujur, kemudian disilangkan pada tiang penyangga dan untuk menguatkan diberi pasak yang terbuat dari besi.

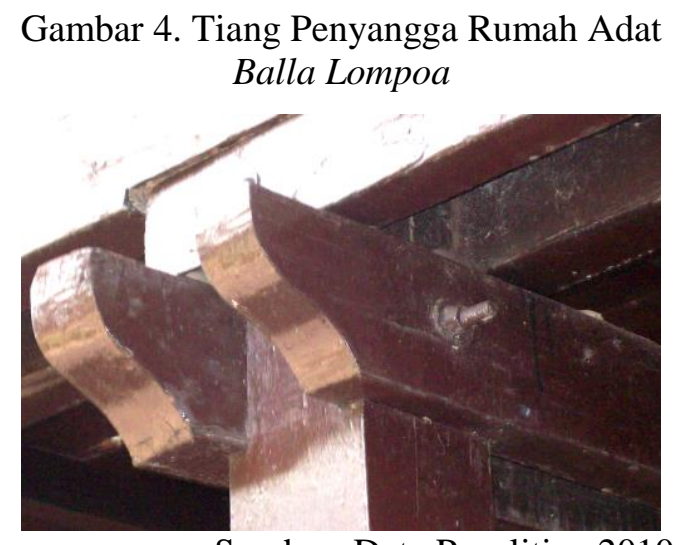

Sumber: Data Penelitian 2010

Bagian passiringan ini sebagai tempat menyimpan kendaraan atau perkakas pertanian pada rumah orang kebanyakan. Bagian bawah rumah adat 
Balla Lompoa saat ini difungsikan sebagai tempat penyimpanan kendaraan yang digunakan pada masa pemerintahan Kerajaan Gowa. Menurut informasi kendaraan bendi ini yang senantiasa digunakan raja dalam kegiatan/perjalanan mengelilingi Gowa.

\section{4) Tangga (tukak)}

Bentuk tangga Balla Lompoa terdiri dari 13 buah anak tangga yang disebut tukak baringan sampulontallu, yang berarti tangga utama yang berjenjang tiga belas. Di samping kiri dan kanan tangga terdapat pegangan yang disebut coccokran tukak pombali. Tangga tersebut memiliki atap (pattongko tukak). Tangga utama menghubungkan bagian bawah dengan rumah induk, yang terbuat dari kayu jati yang cukup kuat dan belum pernah diganti sampai sekarang.

Gambar 5. Tangga Balla Lompoa

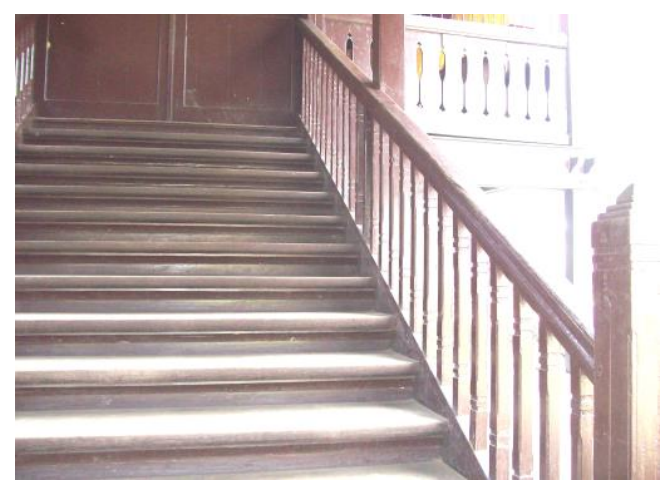

Sumber: Data Penelitian 2010

\section{b. Struktur Bangunan}

Struktur bangunan rumah tradisional Makassar berbeda dengan rumah sukusuku lainnya di Indonesia, terutama suku bangsa yang berdiam di Pulau Jawa. Hal ini disebabkan rumah tradisional Makassar adalah rumah panggung yang menggunakan tiang penyangga dan tidak memakai fondasi. Struktur konstruksi rumah adat Balla Lompoa adalah sebagai berikut:

\section{1) Benteng (tiang)}

Pada rumah Balla Lompoa, tiang penyangga berjumlah 78 buah. Tiang tersebut terdiri atas tiang penyangga badan rumah berjumlah 48 , tiang penyangga serambi (lego-lego) berjumlah 9 buah, dan serambi belakang (dapur) 21 buah. Tiang penyangga serambi ukurannya lebih kecil dibanding tiang penyangga badan rumah.

a) Tiang pertama adalah tempat bersandarnya tangga

b) Tiang kedua adalah pocciballa (tiang pusat rumah) yang merupakan soko guru dari rumah tersebut. Tiang itu terletak pada baris kedua dari depan dan baris kedua dari samping kanan, karena badan rumah Balla Lompoa terdiri dari tiga petak. Tiang yang berada di depan tangga masuk disimbolkan sebagai pengawal atau penjaga rumah. Tiang rumah Balla Lompoa terbuat dari kayu ulin, sangat kuat, terbukti selama Balla Lompoa didirikan belum pernah dilakukan penggantian tiang.

\section{2) Pallangga (penyangga)}

Ada beberapa macam balok yang digunakan pada rangka rumah Balla Lompoa sebagai berikut:

a) Pallangga, terdiri atas pallanga lompo dan pallangga caddi. Pallangga lompo, yaitu balok pipih panjang melilit tiang rumah yang membujur sepanjang badan rumah, berderet dari kiri ke kanan dengan jarak 1 x 1 meter. Pallangga caddi yaitu balok pipih yang dipasang di atas pallangga lompo sebagai penopang lantai rumah ukurannya lebih kecil dibanding pallangga lompo. Balok itu disusun melitang pada badan rumah yang berderet dari depan ke belakang dengan jarak $50 \mathrm{x}$ 50 sentimeter. Pada balok itu dipasang papan sebagai lantai rumah. 
Gambar 6. Balok yang Menjadi Pallangga Caddi dan Pallangga Lompo

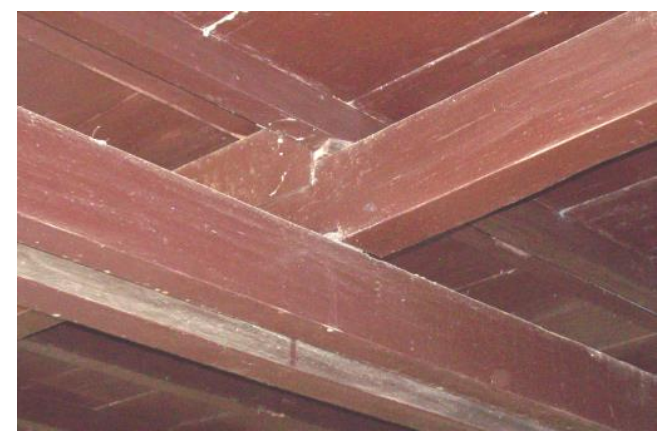

Sumber: Data Penelitian 2010

b) Pattodo adalah balok yang menjadi pasak pada tiang-tiang rumah. Akan tetapi pada rumah adat Balla lompoa, yang menjadi pasak tiang penyangga adalah pasak yang terbuat dari besi. Untuk menguatkan tiang dipasang dua balok yang menjepit keseluruhan tiang rumah.

c) Sompoang adalah balok pipih panjang yang dipasang membujur sepanjang badan rumah dan menjadi tumpuan rangka atap.

d) Padongko adalah balok pipih yang dipasang sepanjang atap rumah pada bagian paling atas, tempat onjong depan dan belakang.

e) Tappi adalah balok berbentuk segi tiga pada samping kiri dan kanan sambulayang.

\section{3) Dapara (lantai)}

Lantai rumah Balla Lompoa yang terbuat dari papan kayu hitam, dipasang membujur sepajang ruangan rumah (paddaserang), berukuran panjang 8 meter dan lebar 60 sentimeter. Setiap ruang dibatasi oleh dinding yang merupakan penyekat antara ruang tamu, ruang tengah, dan ruang belakang.

\section{4) Rinring (dinding)}

Dinding rumah Balla Lompoa terbuat dari papan kayu sebagai penutup dari badan rumah. Dinding menurut letaknya dapat dibedakan:

a) Rinring riolo (dinding depan), yang memiliki jendela depan.

b) Rinring uluang (dinding hulu), yaitu dinding yang terdapat pada bagian kanan rumah.

Gambar 7. Dinding (rinring) Rumah Balla Lompoa

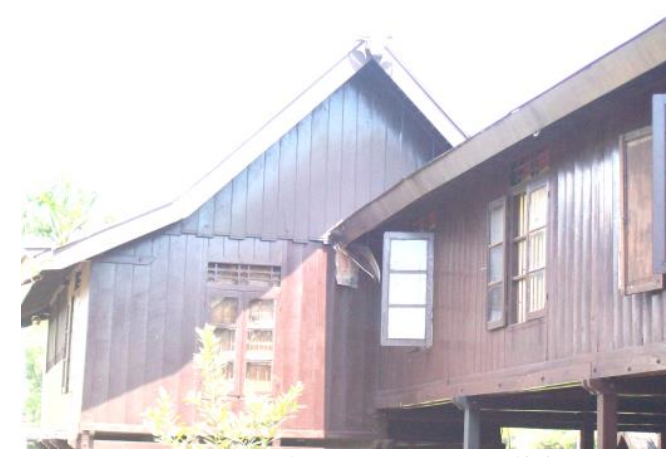

Sumber: Data Penelitian 2010

\section{Ragam Hias}

Ragam hias pada rumah tradisional Makassar merupakan salah satu bagian tersendiri dari bentuk arsitektur rumah tradisional pada umumnya. Ragam hias selain berfungsi sebagai hiasan untuk memperindah rumah juga dianggap mengandung makna yang menjadi simbol budaya masyarakat setempat. Ragam hias pada bangunan Balla Lompoa, secara imaginatif merupakan kebesaran Kerajaan Gowa di masa lampau. Pada umumnya ragam hias mempunyai pola dasar yang bersumber dari alam sekitar manusia. Ada ragam hias yang berbentuk tumbuhtumbuhan (flora), berbentuk binatang (fauna), tulisan Arab atau kaligrafi dan benda-benda alam lainnya.

Ragam hias rumah tradisional Makassar sangat sederhana bila dibandingkan dengan ragam hias rumah tradisional lainnya yang ada di Indonesia. Ragam hias rumah adat Balla Lompoa terdapat pada anjong (bubungan) depan dan belakang, pada dinding teras atau lego-lego, dan pada sambulayang atau tutup bubungan.

Pada bubungan Balla Lompoa terdapat ragam hias kepala kerbau di depan dan 
belakang, baik pada rumah induk maupun pada serambi. Ragam hias tersebut terbuat dari kayu menyerupai kepala kerbau dan diberi cat warna putih dan hitam. Kepala kerbau ini melambangkan kekayaan dan status sosial yang tinggi. Kepala kerbau juga melambangkan persatuan, yang berarti bahwa penghuni rumah tersebut harus mempersatukan dan mengayomi orang-orang di bawahnya. Kepala kerbau juga melambangkan keadilan, berarti seorang raja harus bersikap adil dalam menjalankan pemerintahannya (Tenribali, wawancara 17 April 2010).

Ragam hias yang terdapat pada tutup bubungan berbentuk segi tiga terbalik yang diukir pada tiap tingkatan sambulayang, melambangkan tiga alam yaitu alam atas, alam bawah dan alam inti. Ketiga alam ini mendasari kejadian manusia. Ragam hias berupa flora terdapat pada dinding depan dan samping kiri kanan serambi atau lego-lego, berbentuk buah nenas yang bermakna bahwa penghuni rumah tersebut akan senantiasa mendapat rizki yang manis seperti manisnya buah nenas. Serambi merupakan tempat peristirahatan sejenak sebelum menghadap raja. Di tempat ini ragam hias tersebut dimaksudkan agar yang akan menghadap raja memperlihatkan muka manis dan perilaku baik, agar diterima oleh raja dengan baik pula.

Gambar 8. Ragam Hias Berbentuk Buah Nenas pada Serambi

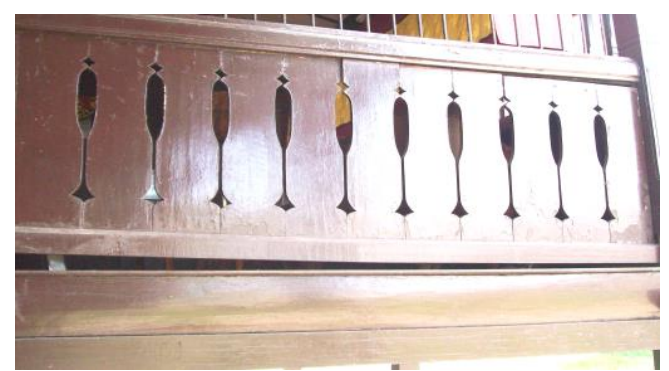

Sumber: Data Penelitian 2010

Pada tiang pegangan tangga (coccorang pombali) terdapat ragam hias yang menyerupai piramida bersusun tiga, ragam hias itu melambangkan stratifikasi sosial orang Makassar, yaitu bangsawan, orang merdeka dan hamba sahaya (ata). Tiang penyangga yang berbentuk segi empat, melambangkan sulapa appa yang berarti kesempurnaan, dimana orang yang akan menaiki atau memasuki rumah adat Balla Lompoa, menjadikan tiang penyangga tangga sebagai tumpuan kesempurnaan sifat-sifat dan perilaku yang baik sebelum menghadap raja.

Gambar 9. Ragam Hias pada Tiang Pegangan Tangga (Coccorang Pombali)

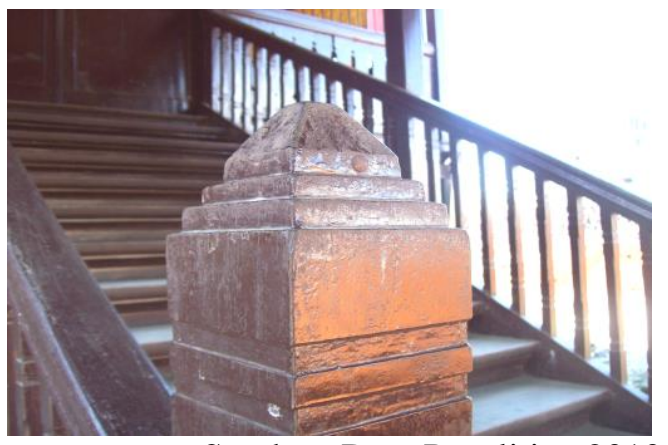

Sumber: Data Penelitian 2010

\section{Kosmologi dalam Arsitektur Tradi-sional Rumah Adat Balla Lompoa}

\section{a. Replika Makro Kosmos}

Masyarakat Gowa memiliki pandangan kosmologis dan berfikir bahwa hidup ini hanya tercapai bila antara makro kosmos dan mikro kosmos senantiasa terjalin hubungan harmonis. Secara fisik, bangunan, bentuk tanah, tiang rumah, dan ruangan umumnya berbentuk segi empat. Bentuk segi empat pada bangunan Balla Lompoa, rupanya tidak sekadar pilihan model sebagaimana umumnya bangunan rumah. Akan tetapi mengandung dasar falsafah sesuai adat Makassar, yang memiliki pandangan bahwa alam semesta itu secara horizontal bersegi empat (sulapa appa). Falsafah sulapa appa bila dikaitkan dengan unsur kehidupan di dunia adalah, api, air, tanah dan angin. Dalam kehidupan bermasyarakat orang Makassar, nilai filosofis ini juga menjadi bagian integral dari nilai etika yang menentukan eksistensi seseorang secara sosial. Pandangan ini tercermin pula dalam struktur bangunan 
Balla Lompoa seperti : areal tanah, bangunan induk mulai dari lego-lego (serambi), kale balla (badan rumah) pammakkang (plafon), benteng (tiang rumah), tontongan (jendela) dan rinring (dinding) rumah.

Secara vertikal kosmos terdiri dari langit, bumi dan pertiwi yang menjadi angka tiga, angka kosmos. Pandangan tiga kosmos ini menandakan ada alam atas sebagai tempat suci, alam tengah sebagai tempat berlangsungnya kehidupan manusia, dan alam bawah sebagai tempat terjadinya interaksi dengan lingkungan sekitar dan makhluk hidup lainnya. Hal ini juga tergambar dalam bentuk rumah adat orang Makassar yang terdiri dari tiga susun, yakni bagian atas rumah yang disebut loteng/pammakkang, bagian tengah merupakan badan rumah (kale balla) dan pada bagian bawah kolong rumah (passiringan).

Makna filosofi dari bentuk ulu balla yang berbentuk prisma segi tiga yang berstruktur tiga, tidak terlepas dari pemaknaan angka tiga yang melambangkan stratifikasi sosial masyarakat Makassar yang terdiri dari bangsawan (raja dan keturunannya), to maradeka (rakyat biasa), ata (masyarakat jelata). Selain itu ulu balla juga bermakna religius. Manusia secara lahir batin ada bagian luar, bagian dalam dan bagian inti, apabila segi tiga itu di lipat dua.

Sambung layang yang bertingkat lima tidak terlepas dari makna bahwa yang menghuni Balla Lompoa adalah penguasa (raja). Kepala kerbau yang terletak pada kedua onjong rumah menunjukkan bahwa pemilik rumah merupakan orang yang terhormat, berdasarkan stratifikasi sosialnya. Kepala kerbau juga melambangkan persatuan yang berarti penghuni rumah tersebut mampu mempersatukan atau mengayomi rakyat yang ada di bawahnya. Demikian pula ornamen yang terdapat pada sambung layang yang berbentuk segi tiga terbalik, juga tidak terlepas dari pemaknaan segi tiga yang telah disebutkan.

\section{b. Refleksi Wujud Manusia}

Pada bagian rumah induk terdapat beberapa ruangan yang direfleksikan sebagai diri manusia (rupa tau). Ruangan depan (paddaserang riolo) disimbolkan sebagai kepala manusia (ulu tau), ruang tengah (paddaserang ritangnga) dianggap sebagai badan manusia, yakni leher hingga perut, dan ruangan belakang (paddaserang riboko) dianggap sebagai kaki manusia.

Paddaserang riolo atau ruang tamu bermakna sebagai kepala manusia, yang digunakan untuk berpikir dan bertindak untuk kepentingan rakyat dan negeri ini, oleh sebab itu, ruangan itu digunakan sebagai tempat untuk bermusyawarah dengan petinggi-petinggi negeri untuk membicarakan berbagai kepentingan rakyat. Sedang paddaserang ri tangnga (ruang tengah) melambangkan badan manusia dari leher sampai pusat, yang bermakna bahwa pada bagian ini digunakan sebagai tempat melaksanakan kegiatan. Paddaserang riboko melambangkan badan manusia dari pusar sampai ujung kaki. Sembilan jendela dimana setiap jendela yang merupakan angka ganjil tertinggi (sembilan) melambangkan bate salapang (sembilan negeri). Menurut pemahaman masyarakat Makassar ada sembilan benda alam yang sangat bersinergi dengan manusia.

Tiang rumah, pada tiang pertama sebagai tempat bersandarnya tangga yang disimbolkan sebagai laki-laki (suami) dan tangga adalah simbol tempat lalu lintas mencari dan membawa rizki untuk sang istri. Tiang kedua adalah pocci balla (tiang pusat rumah). Tiang pusat itu diibaratkan sebagai perempuan (isteri) yang harus menyimpan dan menggunakan rizki yang diperoleh suami. Tiang itu merupakan balok utuh belum dibelah (antero) sebagai simbol agar penghuni rumah tetap utuh, sempurna dan tidak kekurangan.

\section{Orientasi Letak Bangunan}

Arah bangunan Balla Lompoa menghadap ke selatan. Hal itu sesuai dengan pandangan agama Islam, bahwa rumah yang paling baik ialah menghadap 
ke selatan berarti tampingnya (teras samping) di sebelah timur atau yang menghadap ke timur tampingnya di sebelah utara. Arah ka'bah untuk di Indonesia menghadap ke barat, demikian juga arah kaki sewaktu tidur tidak boleh ke selatan, karena sama dengan arah kaki orang mati.

Dahulu orang Makassar beranggapan, bahwa arah rumah boleh saja memilih salah satu dari empat mata angin, tetapi yang paling baik adalah ke arah utara dan timur. Arah timur dianggap baik karena arah terbitnya matahari. Ada anggapan bahwa Tumanurung ketika turun ke bumi berasal dari arah timur dan ketika raib kembali ke arah utara. Berdasarkan anggapan tersebut maka arah rumah yang dianggap baik pada waktu itu adalah arah utara dan timur. Dalam menentukan arah rumah, erat pula hubungannya dengan keadaan tanah di mana rumah didirikan. Bila tanahnya miring ke utara, maka rumahnya harus menghadap ke timur. Hal ini berdasar pada ketentuan adat yang menerapkan bahwa air dari pelimbahan harus mengalir ke kiri, kalau mengalir ke selatan berarti menghanyutkan penghuni rumah jadi arah tersebut dianggap tidak baik. Berarti arah rumah erat hubungannya dengan topografi tanah tempat mendirikan rumah (Mardanas 1985: 39).

\section{PENUTUP}

Arsitektur tradisional Balla Lompoa, mencerminkan arsitektur rumah tradisional suku Makassar yang bentuk dan fungsi ruangannya, disesuaikan dengan nilai estetika masyarakat Makassar. Balla Lompoa diproses dan dirancang sesuai dengan aturan kebiasaan umum yang berlaku turun-temurun dalam wilayah Kerajaan Gowa, sebagai syarat yang harus dipenuhi bagi sebuah rumah adat suku Makassar terutama untuk kediaman raja. Istana Balla Lompoa sempat dihuni oleh dua raja, masing-masing I Mangimangi Daeng Matutu Karaeng Bontonompo Sultan Muhammad Tahir Muhibuddin Raja
Gowa ke-35 Tumenanga ri Sungguna (1936 - 1946), dan Andi Ijo Daeng Mattawang Karaeng Lalolang Sultan Muhammad Abdul Kadir Aididdin (Raja Gowa ke-36) dan menjadi kepala daerah pertama (1946-1960).

Ragam hias yang dimiliki pada bangunan Balla Lompoa secara imaginatif menunjukkan kebesaran Kerajaan Gowa di masa lampau. Ragam hias pada rumah tradisional Makassar umumnya mempunyai pola dasar yang bersumber dari alam, ada ragam hias yang berbentuk tumbuh-tumbuhan (flora), berbentuk binatang (fauna), tulisan arab atau kaligrafi dan benda-benda alam lainnya.

Pada umumnya rumah tradisional Makassar menganut falsafah sulapa appa, yang memiliki pandangan bahwa alam semesta ini secara horizontal bersegi empat yang direfleksikan pada struktur bangunan meliputi areal tanah, bangunan induk mulai dari lego-lego, kale balla, pammakkang, benteng, tontongan dan rinring rumah. Secara vertikal konsep arsitektur tradisional Makassar memiliki pandangan bahwa alam ini terdiri dari tiga kosmos yaitu alam atas, alam tengah dan alam bawah. Falsafah ini direfleksikan dalam bentuk rumah tradisional yang terdiri atas ulu balla, kale balla dan passiringan. Makna filosofi ini terlihat pula pada bentuk ulu balla yang berbentuk prisma segi tiga yang berstruktur tiga yang tidak terlepas dari pemaknaan angka tiga yang melambangkan stratifikasi sosial masyarakat Makassar yang terdiri dari bija karaeng (raja dan keturunannya), to maradeka (rakyat biasa), ata (hamba sahaya). Orientasi atau arah bangunan telah diatur sesuai dengan ketentuan agama dan adat istiadat masyarakat Makassar, untuk menentukan arah rumah erat hubungannya dengan keadaan tanah di mana rumah didirikan.

Keberadaan rumah adat Balla Lompoa merupakan aset yang begitu bernilai bagi masyarakat Sulawesi Selatan dan khususnya Pemerintah Kabupaten Gowa, karena bangunan tua ini memiliki 
keunikan dan sarat dengan makna filosofi. Oleh karena itu arsitektur Balla Lompoa perlu mendapat perhatian dari berbagai pihak termasuk pemerintah agar konsep arsitektur tradisional ini senantiasa mendapat ruang untuk dieskpresikan sebagai warisan budaya bangsa.

\section{DAFTAR SUMBER}

\section{Sumber Tertulis}

Hamid, Abu. 1978.

"Catatan tentang Beberapa aspek Kebudayaan Sulawesi Selatan:

Bingkisan Kebudayaan. No. 4.

Limpo, Syahrul Yasin et al. 1995.

Profil Sejarah Budaya dan Pariwisata Gowa. Gowa: Pemda Tk.II Gowa kerja sama Yayasan Eksponen 1966.

Mardanas, Izarwisma et.al. 1985.

Arsitektur Tradisional Daerah Sulawesi Selatan. Direktorat Jenderal Kebudayaan, Publikasi dan Dokumentasi Kebudayaan Daerah Sulawesi Selatan: Departemen Pendidikan dan Kebudayaan.

Pangerang, Rimba Alam A.et al. 2004.
Legenda Objek Wisata Gowa. Kabupaten Gowa: Dinas Pariwisata Seni dan Budaya.

Patunru, Abd.Razak Dg. 1967.

Sejarah Gowa. Ujung Pandang: Sulawesi Selatan dan Tenggara.Yayasan Kebudayaan.

Tato, Syahriar.2008.

"Arsitektur Tradisional, Warisan Budaya Lokal Sul-Sel “. Makassar: wwwtribuntimurcom@yahoo.com .

\section{Sumber Lisan (Informan)}

Andi Rimba Alam Pangerang, 50 tahun Kepada Dinas Kebudayaan dan Pariwisata Kabupaten Gowa, alamat di Jalan Tumanurung Sungguminasa

Jufri Tenribali, 60 tahun, budayawan, alamat di Jalan Kumala Makassar

Bau Tayang, 70 tahun, Kepala Museum Balla Lompoa, alamat komplek Museum Balla Lompoa

Amir Dg Tarru, 53 tahun, penjaga Museum Balla Lompoa, alamat komplek Museum Balla Lompoa. 